\title{
Didática no Ensino Superior nos cursos de graduação em Estética e Cosmética da Universidade Tuiuti do Paraná.
}

(Didactics for Higher Education in the undergraduate courses in Aesthetics and Cosmetics of the Tuiuti University of Paraná.)

\author{
Marcio Renato Bresciani \\ Instituto Paranaense de Profissionais em Ambiente e Saúde, Curitiba-Brasil \\ Simone Flauzino \\ Instituto Paranaense de Profissionais em Ambiente e Saúde, Curitiba-Brasil
}

Fecha recepción: 01-07-2018

Páginas 26-36

Fecha aceptación: 30-09-2018

\section{Resumo.}

Este estudo ainda em andamento buscou aprofundar conhecimentos para à implantação de projetos nos cursos de graduação em Estética e Cosmética da Universidade Tuiuti. Uma pesquisa qualitativo do tipo bibliográfico descritivo correlacionado ao questionário pré teste em três tópicos a 80 acadêmicos dos cursos de estética e cosmética. Um estudo pertinente tendo em vista a importância da investigação para práxis docente na perspectiva do curso superior. Assim sendo, a relevância se deu pela necessidade urgente em formar novos profissionais éticos conscientes nas área de saúde com responsabilidade como agente transformador da sociedade sob a égide do ensinar e aprender pela pesquisa. Observou-se uma enorme dificuldade por parte dos docentes a necessidade urgente de se adquirir novas competências didáticas no exercício da docência para uma participação mais ativa do discente acadêmico como sujeito pesquisador.

Palavras-chave: didática; pesquisa; aprendizagem; ensino; superior

\section{Abstract.}

This study, still in progress, sought to deepen knowledge for the implementation of projects in the graduation courses in Aesthetics and Cosmetics of Tuiuti University. A qualitative research of the descriptive bibliographic type correlated to the pretest questionnaire in three topics to 80 academics of the courses of aesthetics and cosmetics. A relevant study taking into account the importance of research for teaching praxis in the perspective of higher education. Thus, the relevance was due to the urgent need to train new, conscientious ethical professionals in the area of health with responsibility as a transforming agent of society under the aegis of teaching and learning by research. It was observed an enormous difficulty on the part of the teachers the urgent necessity of acquiring new didactic competences in the exercise of teaching for a more active participation of the academic students as research subject.

Keywords: didática; pesquisa; aprendizagem; ensino; superior 


\section{1.-Introdução.}

As diretrizes nacionais bem como a legislação do ensino superior são pontos iniciais para o processo do ensino de Graduação seja Bacharelado, Licenciatura, superior ou de Tecnologia. No entanto, cada Acadêmico que ingressa aos bancos das faculdades carrega seu próprio conjunto de experiências, interesses e habilidades, e esse conjunto de experiências, interesses e habilidades afeta diretamente a forma de aprender do aluno do ensino superior. Afeta na capacidade de assimilação do que 0 curso de graduação a forma de didática aplicada dos docentes a forma de ensinar. A tarefa hercúlea dos docentes é reunir os alunos e o currículo pensando assim estar construindo um novo aprendizado.

O estudo desde processo de ensino nos cursos de graduação em Estética e Cosmética se dá partir da proposta de um projeto a ser implantado na Universidade Tuiuti do Paraná por meio da pesquisa como forma de ensinar e de aprender.

A problematização neste ensaio é poder responder até que ponto a didática docente dos Cursos de Graduação em Estética e Cosmética, têm fundamento para uma nova práxis de formação científica emancipadora a seus graduandos?

Partindo desta premissa o objetivo buscou pesquisar os efeitos de um programa institucional de pesquisas apoiado academicamente nos conhecimentos necessários a serem construídos na graduação dentro da universidade privada de Tuiuti Paraná.

A justificativa se dá pelo fato da necessidade urgente de formar profissionais capacitados competentes e éticos para a área da saúde, como agentes transformadores da sociedade. A proposta busca sugerir didáticas metodológicas para a investigação cientifica como uma estratégia de ensino eficaz para trabalhar a diversidade de ensinar e aprender.

\section{2.-Modo eficiente para o Ensino e a Aprendizagem.}

Pode-se dizer que cabe aos gestores organizar uma aprendizagem significativa para os alunos, saber administrar a gestão de pessoas, o tempo e o espaço da maneira mais vantajosa. Isso requer envolver conquistar os alunos de várias maneiras, em grupos de estudos de investigação científica, tentando, às vezes formar grupos homogêneos e, outras vezes, grupos mistos até envolver alunos.

Entretanto, situação com formação e experiências diversificadas, podem favorecer os docentes que conduzem grupos de pesquisa se apropriam de uma didática que considere as múltiplas dimensões do seu complexo objeto o processo de ensinar e aprender situado em contextos múltiplos que deem suporte ao ensino de graduação, ao currículo, às disciplinas e as atividades de pesquisa.

Segundo Soares (2013) diz que pode haver oportunidades os alunos próprios alunos aprenderem, utilizando recursos materiais como as mídias sociais e multimeios 
midiáticos, sendo que essa oportunidade provavelmente aumentará na medida em que mais programas forem produzidos com a finalidade de provocar sobre 0 ensinar e 0 aprender em suas diferentes didáticas e metodologias.

Todo pedagógico necessariamente deve ser imbuído de uma política global quanto às oportunidades iguais para todos os acadêmicos. Não é só uma questão de oportunidades iguais no que tange a gênero, raça, credo, formação profissional prévia anterior à graduação e até mesmo alguma deficiência de aprendizagem ou deficiência aparente mesmo como: surdez, cegueira, TEA, TDAH ou outra deficiência.

Contudo, a inclusão deve estar explicita nos planejamentos de aulas e a pesquisa poderá desenvolver novas competências aos alunos. A inclusão de alunos com deficiência no ensino superior é uma nova realidade repleta de desafios. Essa nova demanda no ensino superior trouxe consigo a necessidade de reestruturação e adaptação não somente da didática e da metodologia de ensino, mas também de uma nova realidade tanto para os professores quanto para os acadêmicos e seus colegas envolvidos nesse processo Corrêa (2014).

\section{1.-Dificuldade na Aprendizagem.}

Pimenta (2010) diz que a base do conhecimento se assenta na técnica e no processo educativo numa espécie de controle. E o que pretende despertar aqui é a atenção para a avaliação da aprendizagem pela investigação com resultados plausíveis, fundamentados na pesquisa conceitual a partir de contextos reais vivenciados ou não pelos próprios alunos e professores. Assim sendo, o aluno não será controlado por notas, conceitos, mas serão avaliados por argumentação fundamentação teórica e investigação por meio de coleta de dados, tabulação e discussão dos resultados.

Ne verdade o que tem presenciado ao longo do processo de graduação tem sido 0 de autoritarismo do "saber científico" o que retira o potencial de construção de conhecimentos, a partir das relações de ensinar e aprender em contextos. E justifica 0 fracasso nas aprendizagens como decorrente da incapacidade para aprender daqueles que fracassaram nos cursos de graduação. No entanto, nas práticas didáticas docentes atividades formativas dos sujeitos que ensinam e que aprendem, há múltiplas dimensões pedagógicas, que incluem e extrapola a sala de aula, para a didática, que tem seu suporte na teoria pedagógica parte da práxis educativa Pimenta (2010).

Que na verdade o se deveria perceber seria o contrário para uma perspectiva coletiva interdisciplinar dos referidos contextos, que se desenvolva uma educação de qualidade na pratica dos cursos de graduação, vem mostrando sucesso nos resultados de qualidade do conjunto dos estudantes de universidades que têm criado novos arranjos curriculares, com atividades que mobilizam a relação dos sujeitos, 
ensinantes e aprendentes críticos e reflexivos, com os conhecimentos científicos das áreas Pimenta (2010, p. 45).

Quando o aluno participa como construtor a aula apresenta "melhoras em equipe", mas problematizando e oportunizando novos olhares sob a perspectiva do olhar científico, onde 0 aluno se responsabiliza pela sua formação e deixa de ser um mero expectador em sala.

Nesse sentido, a proposta de formação que se referenda neste estudo, se reveste de um forte cunho político, na perspectiva de se defender a formação de profissionais comprometidos com a superação da sociedade capitalista e, por conseguinte, de todos os malefícios que ela impõe às classes que trabalham para mantê-la. Outrossim, as proposições em questão parte da consideração de que uma formação política não prescinde da qualificação técnica, isto é, de se garantir aos estudantes 0 domínio de conhecimentos de cunho didático pedagógicos que os habilite a concretizar tal formação política nos estabelecimentos de ensino da educação básica.

Sendo assim, a prática pedagógica, por ser política, exige competência técnica Candau, (2011, p. 34). No entanto a competência técnica sem conhecimento didático se torna efêmero e impossibilita 0 aprendizado, pois faltará ao docente por exemplo, técnicas diferenciadas de avaliação que oportunizem aos alunos com dificuldade de aprendizagem e demonstrarem seus conhecimentos por meio de diferentes instrumentos avaliativos que vão muito além da fatídica "prova".

\section{3.-A nova práxis educativa.}

Os saberes ensinados pela pesquisa são reconstruídos pelos educadores e educandos coletivamente e, a partir dessa reconstrução, esses sujeitos têm possibilidade de se tornarem autônomos, emancipados, questionadores.

Para Pimenta (2010) situados em contextos que Ihes garantam condições institucionais e de trabalho para o exercício digno de suas atividades de ensinar e aprender, professores e alunos, conseguem esse nível de qualidade ponto de partida que qualquer atividade educativa, intencional ou não, é objeto de estudo do aprender e do ensinar.

Portanto, o currículo, as disciplinas e demais atividades nela se situam enquanto intencionalidade de compreender as relações entre ensinar e aprender e contribuir para tornar essa relação emancipadora dos sujeitos nelas envolvidos. Portanto, a práxis se torna real quando se reforça, assim, a ideia de que a formação do docente do ensino superior não pode ficar apenas vinculada ao conhecimento de conteúdo específicos, pois se existe a concomitância de profissões 0 que pode ser muito benéfico, ambas precisam ser exploradas, ou seja, efetivamente aproveitadas em sala de aula. Ser um bom professor do ensino superior significa, portanto, mais do 
que ter facilidade em transmitir o que se sabe. Exige conhecimento específico, exige técnica e aperfeiçoamento contínuo.

A nova práxis educativa permeia a construção de competências profissionais docentes com vistas à resolução de situações problema e a um saber-fazer que privilegie as aprendizagens específicas e necessárias à atuação profissional para a incerteza e a imediaticidade do cotidiano da educação superior.

\section{3.-Metodologia.}

A pesquisa se utilizou do enfoque qualitativo a qual buscou compreender a perspectiva dos participantes acerca dos fenômenos que os rodeiam, aprofundar suas experiências, perspectivas, opiniões e significados, ou seja, a forma em que os participantes percebem subjetivamente sua realidade. Hernández Sampieri, Collado e Lucio (2010, p. 245).

O método consiste no fenomenológico do tipo descritivo, para Guerra (2016), "apreender a lógica dos fenômenos subjetivos, conforme Oliveira (2007), correlacionando a um Pre-test questionário por categorias aplicado aos acadêmicos dos cursos de (Estética e Cosmética).

A população total compreende 250 alunos, a amostra inicial para a coleta dos dados se deu junto a 80 alunos para um análise prévio dos dados/contato direto com as teorias afins que tratem do tema em estudo. O questionário buscou saber as expectativas dos acadêmicos quanto: A qualificação docente e a dificuldade de aprendizagem dos novos acadêmicos;

O estudo fez um recorte quanto os dados coletados conhecimentos quanto a didática de ENSINAR nos cursos de Graduação de Estética e Cosmética aplicada junto aos alunos do $3^{\circ}$ semestre da Universidade Tuiuti Curitiba-Paraná.

\section{4.-Discussão dos resultados.}

A revisão teórica bibliográfica alicerçou as análises da coleta dos dados junto aos acadêmicos dos cursos de Estética e Cosmética tendo a amostragem de 80 acadêmicos do $3^{\circ}$ semestre:

As Categorias investigadas:

1. A qualificação docente e a dificuldade de aprendizagem dos novos acadêmicos.

2. Contribuição acadêmica na apresentação do projeto de iniciação científica no ensino superior.

3. Os direitos humanos para a prática em saúde.

O intuito da pesquisa foi apontar subsídios para a melhoria da didática docente, bem como, contribuir para com o trabalho da coordenação ao se aplicar bons projetos que 
vão desde o Ensinar com a pesquisa/ Pesquisar o ensinar a partir de metodologias ativas baseada em situações reais. Um trabalho a partir das temáticas propostas para o ensino na área da saúde especificadamente nos curso de graduação superior em tecnologia e Estética e Cosmética. Pois a ideia é criar e estabilizar hábitos de reflexão, efetivando o fazer parte da prática profissional docente pelo menos no curso de graduação de estética e cosmética.

Das entrevistas prévias se fez um recorte distribuiu-se os resultados coletados em três tópicos básicos (categorias) pontuando-os de maior frequência partir do trabalho desenvolvido até 0 atual momento.

Tabela 01: A qualificação docente e a dificuldade de aprendizagem dos novos acadêmicos.

\begin{tabular}{l|l}
\hline \multicolumn{2}{l}{ Qualificação docente e dificuldades na aprendizagem } \\
\hline \multirow{2}{*}{ Resposta } & $\begin{array}{l}\text { Os quesitos que se refere a qualificação requer uma nova didática de } \\
\text { ensino, esta será de fundamental importância para o corpo docente } \\
\text { uma vez que poderá contribuir para minimizar uma formação } \\
\text { insuficiente no ensino superior quanto ao que se refere ao } \\
\text { pensamento crítico bem como, à prática aos tratamentos e aos } \\
\text { novos procedimentos estéticos. }\end{array}$ \\
\hline
\end{tabular}

Fonte: A própria pesquisa.

Segundo dados durante o período de curso de graduação os acadêmicos se deparam com diferentes níveis de formação de professores desde a área da saúde, beleza e bem-estar, Tecnólogo em Estética e Fisioterapeutas, outros Biomédicos, Farmacêuticos, Biólogos e alguns de áreas diversas como Educadores Físicos, Nutricionistas. Porém, a maioria dos docentes todos trabalham durante 0 dia em clínicas e chegam a noite à sala de aula para ensinar muitos o que vivenciaram durante 0 trabalho.

Profissionais que repassam seus conhecimentos técnicos para que o aluno os use em sua futura profissão. No entanto, 0 interesse pela docência exige desses professores uma formação didática, que responda às expectativas de desenvolver competências que vá ao encontro do que se quer de fato: ser professor de ensino superior. Indo além de ensinar aquilo com o que trabalho forma e contribui, adquirindo um conhecimento pedagógico para melhor desenvolver as aulas.

Segundo Pimenta (2010) se faz necessário o diálogo e a reflexão para não gere expectativa tecnicista (por parte das disciplinas); uma formação fragmentada; ausência de análises sem que se perceba a totalidade por falta de conhecimento (da área que se pretende ensinar em consonância com o projeto pedagógico do curso); reiteraria uma concepção positivista do fenômeno e uma tentativa de se elaborar a partir das áreas, explicações que se pretendem únicas. O necessário é desenvolver 0 ensino científico para desfragmentar o conhecimento, minimizando assim as dificuldades de aprendizagem. 
Todavia, os planos elaborados pelos docentes, não podem e nem devem ser cópias das ementas e replicadas ano após ano. Precisam ser avaliadas a cada nova turma, até mesmo depois de iniciar o trabalho com os alunos.

Pode-se dizer que a pedagogia tecnicista baseia-se num modelo de racionalidade técnica que separa teoria e prática, reflexão e ação, conteúdo e forma de ensino e pesquisa. Enfim, separa quem planeja e quem executa. Para Pimenta (2010) isso por consequência forma profissionais fragmentados sem entender a própria profissão. No caso do esteticista que atua na área da saúde, a consequência de conhecimento fragmentado, é de um profissional irresponsável por não ter real consciência da seriedade dos procedimentos estéticos faciais e corporais. Dessa forma acarreta a danos à saúde de seus clientes podendo ser irreversíveis.

Caso o professor que ainda não possua a formação pedagógica, conduz suas aulas a partir da problematização real e o ensino passa a ser reduzido à formulação de objetivos educacionais e instrucionais, com o predomínio da utilização de técnicas mediante uma prática formal e funcionalista. A instituição de Ensino Superior visa apenas índices em sua eficiência, apenas por números e na realidade os objetivos reais não condiz com o posto no papel.

Tabela 02: Contribuição acadêmica na apresentação de um projeto no ensino superior.

\begin{tabular}{l|l}
\hline \multicolumn{3}{l}{ Contribuição acadêmica durante o processo de construção } \\
\hline \multirow{3}{*}{ Respostas } & $\begin{array}{l}\text { É possível e relevante para o processo de construção do } \\
\text { conhecimento quando se busca a participação coletiva se pode } \\
\text { evidenciar e validar a escala de maior eficiência e eficácia para a } \\
\text { formação de novos docente no ensino superior principalmente } \\
\text { quando se trata de saúde (estética e cosmética). }\end{array}$ \\
\hline
\end{tabular}

Fonte: A própria pesquisa.

Assim, a pesquisa científica segundo Demo (2006) deve ser princípio educativo, ser uma "conquista" e não uma "domesticação" aborda a diferença entre a pesquisa como princípio científico e a pesquisa como princípio educativo:

"Pesquisa como princípio científico e educativo faz parte de todo processo emancipatório, no qual se constrói o sujeito histórico autossuficiente, crítico e autocrítico, participante e capaz de reagir contra a situação de objeto e de não cultivar o outro como objeto. Pesquisa como diálogo é processo cotidiano integrante do ritmo de vida, produto e motivo de interesses sociais em confronto, base da aprendizagem que não se restrinja a mera reprodução; na acepção mais simples, pode significar conhecer, saber, informar-se para sobreviver, para enfrentar a vida de modo consciente" Demo (2006, p.42-43).

O aprender pela pesquisa transforma 0 aluno, faz ele sair na condição de mero ouvinte, copiador, para ser um ser livre no que diz respeito à escolha de temas para elaboração própria. 0 docente que se apropria da pesquisa para 0 ato de ensinar 
tem a responsabilidade de incentivar seus alunos acadêmicos, a não aprender pela repetição, mas ensina a estudar para saber e também para atuar na vida e na profiss.

Para Delorz (2003) o aprender a aprender, que significa não imitar, copiar, reproduzir. A verdadeira aprendizagem é aquela construída com esforço próprio por meio da elaboração pessoal. O ensino na graduação por meio da pesquisa precisa superar seu formalismo regrado e distanciado do compromisso de motivar 0 processo educativo.

A pesquisa como instrumentação da descoberta e elaboração própria e indutora da motivação ao questionamento e diálogo. Assim, o ensinar na graduação precisa estar em sintonia com práticas de ensino e de aprendizagem que recuperarem e ocupem 0 seu real papel social: educar para a cidadania.

Para tanto, destacam-se os princípios articuladores da pesquisa. As atividades que compõem o ensino resultam melhor quando envolvidas em: processos investigativos; processos dialogais na sala de aula que incorpora ao existir o sentido de criticidade; na construção de processos de práxis; na construção de processos de mediação e considerar os processos de redes de saberes Pimenta (2010, p. 33).

Tabela 03: Sobre os Direitos humanos para a prática em saúde.

Conhecimentos sobre direitos humanos na prática em saúde.

\begin{tabular}{l|l} 
Resposta & A maioria das turmas do curso superior em Estética e Cosmética, \\
Eixo Tecnológico, ambiente e saúde, acreditam que o ensino sobre
\end{tabular} direitos humanos é importantíssimo para a prática posterior em saúde, quando se passa a aplicar procedimentos que devem respeitar os direitos éticos em cada procedimento principalmente os de tratamentos estéticos.

Fonte: dados da pesquisa.

Para o ensinar cabe uma reflexão que fora abordada até agora na ação do ato de ensinar especificidade do trabalho docente ou em qualquer nível de escolaridade, ou melhor: A ENSINAGEM, significa que. "Apreender não é um processo que se efetive sem rotinas ou ocorra de forma espontânea ou mágica. Ao contrário, exige, exatamente, em virtude da intencionalidade contida no conceito de ensinagem, a escolha e execução de uma metodologia adequada aos objetivos e conteúdo do objeto de ensino aos alunos. Exige-se do professor, além do domínio do conteúdo a ser ensinado, a competência para uma docência da melhor qualidade" Pimenta (2010; p. 211).

Já Soares (2013) ressalta a importância da sensibilidade, das atitudes, dos valores, da reflexão por parte do professor comprometido com o processo de ensinagem "(...) entende-se a professoralidade como um processo que implica não só o domínio de conhecimentos, de saberes, de fazeres, de determinado campo, mas também a sensibilidade do docente como pessoa e profissional em termos de atitudes e 
valores, tendo a reflexão como componente intrínseco ao processo de ensinar, de aprender, de formar-se e, consequentemente, desenvolver-se profissionalmente." Soares $(2013$, p. 3).

Logo a reflexão trazida até aqui pode ser gerada a partir de diferentes objetos ou situações vivenciadas em situações concretas e ocorre em níveis e conceitos cognitivos variados no que tange o público alvo dessa pesquisa que são os egressos dos cursos de graduação em Estética e Cosmética. Neste ensaio foi observado 0 conjunto de conhecimentos necessários ao professor para ensinar e quais conhecimentos que os alunos podem, por meio da sensibilidade do professor, serem aproveitados nas aulas.

Os conhecimentos didáticos possuem diferentes naturezas, mas todos eles são essenciais para atuação do professor como profissional: conhecimentos sobre 0 contexto dos seus alunos e suas características pessoais; conhecimento específico da disciplina que irá lecionar, e, mesmo num curso superior de tecnologia, necessários conhecimentos sobre as questões pedagógicas e do contexto em que a aprendizagem se insere Freire (2011, p. 78)

No entanto, os professores do ensino superior de modo geral enfrentam dificuldades para ensinar aos alunos em um mundo de motivação restrita em sala de aula devido a tecnologia da informação. O Baixo nível de habilidades para a resolução de situações problemáticas, por falta de domínio técnico do próprio conteúdo, bem como, de tecnologias em constante modificação. Não obstante o professor que não estiver em constante busca, pesquisa, investigação para tornar eficiente o processo ensino-aprendizagem e mais motivador 0 ambiente acadêmico, terá frustrado o seu resultado e não atingirá o objetivo de aprendizagem real e verdadeira do aluno do ensino superior. E passarão a ser corresponsáveis de engodos pedagógico onde, Ruben Alves (2001), fazem de conta que ensinam e os alunos fazem de conta que aprendem. Uma lástima isso!

Desta forma, a aprendizagem se constitui num processo solitário e como sublinham Santos e Praia (1992) "ela parte da convicção de que os alunos aprendem, por conta própria, qualquer conteúdo científico, a partir da observação". Segundo os autores, 0 professor ilude-se a si mesmo e a seus alunos quando sugerem que eles podem descobrir sozinhos os conceitos por meio do método científico. Deve-se acrescentar que, nesta perspectiva, o método científico requer do aluno, entre outras características, a opacidade de observação, de formular problemas, elaborar e verificar hipóteses formuladas e, a partir da confirmação ou constatação destas hipóteses, ampliar os conhecimentos, ou seja, constituir o conhecimento científico Demo (2006, p. 23).

\section{5.-Conclusão.}

Os resultados apontaram que esse tipo de projeto poderá ser usado como ponto de partida para a formação acadêmica dos futuros docentes bem como, contribuir de 
forma significativa para revisão de práticas e ações didáticas docente, incluindo a reflexão orientada e efetiva no ensino superior desta forma a universidade estará contribuindo para uma nova formação um novo profissional docente graduado em estética e cosmética com uma nova política didática institucionalizada.

Ainda, pode-se evidenciar quais conhecimentos são mais necessários para o ensino e aprendizagem no ensino superior por meio da investigação científica também se evidenciou muitas reflexões, desde a preparação das aulas a serem ministradas numa interação (professor alunos $x$ alunos professor), onde o professor deixa de ser 0 detentor do conhecimento e 0 aluno mero expectador, para que se efetive a construção do conhecimento

Assim sendo, novos conhecimentos são fundamentais para mobilizar mais e mais acadêmicos para a necessidade de reforçar contexto específico reais para um novo processo de aprendizagem no curso de graduação de estética e cosmética da Universidade Tuiuti Paraná.

\section{6.-Referências.}

Candau, V.M.F. (2011). A didática em questão. Petrópolis: Vozes.

Corrêa, P.M. (2014). Acessibilidade no ensino superior: instrumento para avaliação, satisfação dos alunos com deficiência e percepção de coordenadores de cursos. Doutorado em Educação 283, p. Tese. Universidade Estadual Paulista. Marília: UNESP.

Delors, J. (2003). Educação, um tesouro a descobrir: relatório para a UNESCO da Comissão Internacional sobre educação para o século XXI. 8aed. Brasília: Ministério da Educação e Cultura.

Demo, P. (2017). Educação emancipatória precisa de educação científica. Mato Grosso do Sul: Secretaria de Estado da Educação.

Freire, P. (2011). Pedagogia da autonomia: saberes necessários à prática educativa. São Paulo: Paz e Terra.

Hernández Sampieri, R., Collado C. F., Lucio, P.B. (2010). Metodologia de Pesquisa. 3 ed. São Paulo: Mcgraw-Hill.

Oliveira, M.M. (2007). Como fazer pesquisa qualitativa. Petrópolis: Vozes.

Pimenta, S.G. (2010). Professor reflexivo: construindo uma crítica. In: Pimenta, S.G., Ghedin, E. (Orgs.). Professor reflexivo no Brasil: gênese e crítica de um conceito. São Paulo: Cortez. 
Santos, M.E., Praia, J.F. (2017). Percurso de mudança na didática das ciências sua fundamentação epistemológica. In: Cachapuz. Ensino de Ciências e Formação de Professores n.1, p.7-34. Santiago: Departamento de Didática e Tecnologia Educativa da Universidade de Aveiro.

Soares, I.O. (2013). Educomunicação: As múltiplas tradições de um campo emergente de intervenção social, na Europa, Estados Unidos e América Latina. São Paulo: Dicionário INTERCOM. 